\title{
ANALYTICAL METHOD BY HPLC-DAD ALLOWS QUANTIFICATION OF QUERCETIN MARKER IN STANDARDIZED EXTRACT OF ANADENANTHERA COLUBRINA VAR. CEBIL
}

\author{
VALMIR GOMES DE SOUZA ${ }^{a^{*}}$, FABRÍCIO HAVY DANTAS DE ANDRADE ${ }^{\mathrm{b}}$, FABIO SANTOS DE SOUZA, \\ RUI OLIVEIRA MACEDOa,b
}

\begin{abstract}
aDepartment of Pharmaceutical Sciences, Medicine Development and Assays Unified Laboratories, Federal University of Paraíba, João Pessoa, PB, Brazil, bDepartment of Pharmaceutical Sciences, Federal University of Pernambuco, Recife-PE, Brazil Email: valmirfarmaceutico@gmail.com
\end{abstract}

Received: 05 Dec 2016 Revised and Accepted: 19 Jun 2017

\begin{abstract}
Objective: The Anadenanthera colubrina (Vell.) Brennan var. cebil is a medicinal plant that has been used for the treatment of many diseases in the northeastern region of Brazil. This plant contains secondary metabolites such as quercetin, a flavonoid that is known by its antioxidant and antiinflammatory effects. The aim of this work is to propose the validation of an analytical method using high-performance liquid chromatography with diode array detector (HPLC-DAD) for the quantification of quercetin and standardization of the hydroalcoholic extract (HAE) of $A$. colubrina.
\end{abstract}

Methods: The A. colubrina extracts were prepared by the maceration process with powdered leaves at $20 \%$ weight: volume (w/v) and a hydroalcoholic solution at $50 \%$ volume: volume $(\mathrm{v} / \mathrm{v})$ for $120 \mathrm{~h}$ at room temperature. After pretreatment of the hydroalcoholic extract, the quercetin marker was used for quantification and proceeded to the evaluation of validation parameters for the method using HPLC-DAD.

Results: The analytical method proved to be specific. Linear over the range $1.4-26.6 \mu \mathrm{g} / \mathrm{ml}$, regression analysis showed a good correlation coefficient (R2= 0.999); the limit of detection (LOD) and the limit of quantification (LOQ) were $0.27 \mathrm{and} 0.81 \mu \mathrm{g} / \mathrm{ml} \mathrm{respectively.} \mathrm{The} \mathrm{relative}$ standard deviation (RSD) did not exceed $2.5 \%$ for precision. The proposed method was validated with an average recovery of $92.5-97.5 \%$.

Conclusion: The method was validated using HPLC-DAD, allowing the quantification of quercetin in the standardisation process of extracts and quality control of the herbal drug containing A. colubrina Phyto complex.

Keywords: Validation, Analytical, Method, Quercetin, Flavonoid, Anadenanthera colubrina

(C) 2017 The Authors. Published by Innovare Academic Sciences Pvt Ltd. This is an open access article under the CC BY license (http://creativecommons.org/licenses/by/4.0/) DOI: http://dx.doi.org/10.22159/ijpps.2017v9i8.16468

\section{INTRODUCTION}

Anadenanthera colubrina (Vell.) Brenan var. cebil (Griseb) Altschul (Fabaceae/leguminosae is a native plant detected in the South American continent and distributed throughout Paraguay, Argentina, Bolivia, and Brazil [1-2]. Popularly known by the names yopo, cohoba, vilca, and angico, this plant has economic, cultural, and medicinal importance [3-4]. Hydroalcoholic extracts and decoctions of the leaves and bark of $A$. colubrina are used in the treatment of gastric and respiratory tract infections and others inflammatory diseases. It is classified among one of ten medicinal plants most frequently used by the communities living in the bioma named Caatinga located in northeastern Brazil [5-6].

Preclinical studies of the healing and antimicrobial activities of $A$. colubrina extracts endorse their popular usage [7-9]. These assays also demonstrated anti-inflammatory mechanisms, such as the decrease of the production of pro-inflammatory cytokines, inflammatory mediators, increased tyrosine kinase production, and healing action by reducing the synthesis of polymeric collagen and acidic glycoproteins that make healing difficult, and thus contributing to the development of a phytotherapeutic medicinal products with safety and therapeutic efficacy [10-13]. Research on the quality of a herbal drug is not based solely on clinical effects but also on the standardization of plant extracts through quantitative analyses using active ingredients and secondary metabolites called biomarkers [14-16].

The development of analytical methods must be based on fundamental conditions such as sampling, pretreatment sampling, and the evaluation of validation parameters in order to guarantee the quality, consistency, and reliability of the analytical results [1718]. The pretreatment of samples is a decisive step in the development of the analytical methods of constituents in biological matrices and must guarantee the release of the analytes of the complex matrix, to be monitored by analytical signals with appropriate instrumentation [19-21]. Some matrices of plant's components may behave as interferers, which impair the identification and quantification of biomarkers, in addition, these interferers may compromise the performance of chromatographic systems [18, 21-23].

A sample clean-up procedure improves analytical sensitivity, enables more robust reproducible results, and preserves the life of chromatographic columns [24-26]. Chromatographic techniques such as HPLC (High-Performance Liquid Chromatography) present advantages for efficiency separation and the identification of compounds when associated with detection systems appropriate to the chemical nature of the analytes, providing qualitative and quantitative information about Phyto-complex components [27-28]. A. colubrina has a large amount and class of secondary metabolites: tannins; alkaloids; flavonoids such as quercitrine; isoquercetrine; apigenin; quercetin; and other phenolic compounds [29-33].

Several analytical methods have been reported for the analysis of flavonoids in the extracts of medicinal plants [34-35]; however, they cannot be used as general methods for analysis due to the complexity of each vegetable plant species and the variability of factors that could influence their chemical composition [36-37]. Until now, no method validated by HPLC-DAD for quercetin quantification of HAE of $A$. colubrina has been reported in the literature. Properly validated analytical methods allow reproducible qualitative and quantitative analyses and ensure consistency of the analytical quality of a medicinal product $[29,38]$. In this research, a methodology will be developed for extracting the biomarker quercetin in the phytocomplex of $A$. colubrina and an analytical method for the quantification of quercetin in that plant's extract will be validated, according to the ICH (International Conference on Harmonisation) Q2 (R1) guidelines for HPLC-DAD [39-40]. 


\section{MATERIALS AND METHODS}

\section{Reagents and materials}

The quercetin standard (Cas 117-39-5) was purchased from Sigma Alldrich $^{\circledR}$, Brazil, methanol HPLC grade was purchased from Tedia ${ }^{\circledR}$, USA, orthophosphoric acid was purchased from Merck ${ }^{\circledR}$, Germany, ethanol $96 \%$ was purchased from Toscano ${ }^{\circledR}$, Brazil, dichloromethane hplc grade and hexane were purchased from Vetec ${ }^{\circledR}$, Brazil.

\section{Drug identification plant}

The Anadenanthera colubrina var. cebil leaves were collected from cacimbas farm, Caraúbas county located in the micro region of cariri in the state of Paraiba (Lat. $7^{\circ} 30^{\prime} 48.1^{\prime \prime}$; ; Long. $36^{\circ} 41^{\prime} 81.0^{\prime \prime} 0$ ) in May 2015. The research project with A. colubrina received authorization from the Ministry of Environment of Brazil (ICMBio \SISBio \MMA-Brazil) for activities with scientific purpose $\mathrm{n}$ $\circ 41277-2$. The exsiccatae of the plant species was deposited in the herbarium Lauro Pires Xavier, UFPB Joao Pessoa, Brazil, under the number NC262.

\section{Plant drug drying}

The Anadenanthera colubrina var. cebil leaves were dried in a greenhouse with circulating air $\left(\mathrm{Tecnal}^{\circledR}\right.$, model TE 394-4), under a temperature of $40 \pm 2$ degrees celsius $\left({ }^{\circ} \mathrm{C}\right)$ by $3 \mathrm{~d}$.

\section{Obtaining the sprayed plant drug}

The dry plant drug was submitted to a vertical rotor mechanical mill (Tecnal ${ }^{\circledR}$ Modelo TE-631-3). The powdered vegetable drug was packed in a hermetically sealed plastic bag protected from light and moisture.

\section{Obtaining hydroalcoholic extract (HAE)}

The extraction was established from the ratio of $20 \%$ weight: volume $(\mathrm{w} / \mathrm{v})$ from the mass of the sprayed vegetable drug and the extractive solvent system. The extraction system was defined using a proportion of hydroalcoholic solution at 50:50 volume: volume (v/v), and the extraction method utilised was maceration.

\section{Chromatographic conditions}

We used HPLC-DAD system prominence series by SHIMADZU ${ }^{\circledR}$, Japan, control system was performed by software LC Solutions ${ }^{\circledR}$; octodecilsilano C-18 stationary phase Gemini nx 5 micrometers $(\mu \mathrm{m})$ 150 x 4.6 millimeters x $0.5 \mu \mathrm{m}$; pre-column gemini C-18 4 × $3.0 \mathrm{~mm}$; membrane-filtered mobile phase PTFE $0.45 \mu \mathrm{m}$ and degassed: methanol: phosphoric acid 1\% (47: 53\%). mobile phase flow: 1.2 $\mathrm{ml} / \mathrm{min}$; Oven temperature at $40^{\circ} \mathrm{C}$; monitored wave number at 370 $\mathrm{nm}$; injection volume 20 microliters $(\mu \mathrm{L})$; chromatographic run time $30 \mathrm{~min}$.

\section{Development of the analytical method}

An analytical method was validated by HPLC-DAD for the quantification of quercetin marker in extract samples of $A$. colubrina. The ICH Q2-R1 guidelines [34] were observed in the evaluation and validation parameters for analytical procedures: specificity, selectivity, linearity, limit of quantification and detection, precision, accuracy, robustness, and stability. Deviations of up to $5 \%$ were considered in the statistical evaluation of the data.

The choice of quercetin marker was based on bibliographical researches of phytochemical compositions [31-32] and preliminary tests of characterization of the variant A. colubrina extract, which indicated the same as the majority. An analytical extractive procedure was developed to guarantee clean-up, pre-concentration, exhaustive extraction of the marker, and elimination of possible interferences of the fraction to be injected into the chromatographic system.

In the development of the marker recovery method, continuous multiple extraction was employed and liquid-liquid extraction (ELL) was used by the agitation system (Vortex model AP-56 Phoenix ${ }^{\circledR}$ ) of threated tubes with caps of 10 milliliter $(\mathrm{ml}) \mathrm{n}{ }^{\circ} 9825\left(\right.$ Pirex $^{\circledR}$, Mexico) and the use of centrifugation (Centrifuge $80-2 \mathrm{~B}$, Macro ${ }^{\circledR}$ ) with rotation of 4000 revolutions per minute (RPM) during $10 \mathrm{~min}$ to separate the phases.

\section{Determination of the analysis factor}

The analysis factor was determined due to successive dilutions made in multiple extraction continued and allowed to quantify the content of the chemical marker present in the extract in micrograms per milliliter $(\mu \mathrm{g} / \mathrm{ml})$.

The Equation 1 below shows how to determine the concentration of the marker in the HAE.

$$
\mathrm{Ca}=\mathrm{Cp} \times \mathrm{FA} \times \mathrm{Aa} \div \mathrm{Ap}(1)
$$

Hence:

$\mathrm{Ca}$ is the concentration of the quercetin biomarker in the HAE sample, expressed in micrograms per milliliters $(\mu \mathrm{g} / \mathrm{ml})$,

Aa is the area of the chromatographic peak marker on HAE,

Ap is the quercetin standard chromatographic peak,

$\mathrm{Cp}$ is the concentration of the chemical reference substance quercetin,

FA is the analysis factor and is calculated by equation 2 :

$$
\mathrm{FA}=\mathrm{Ta} \div\{[(\mathrm{Ta} \div \mathrm{Fec}) \times \text { Fevap }] \div \text { Vrec }\}(2)
$$

Hence:

$\mathrm{Ta}=$ HAE Sample Taking

Fevap = Organic Fraction Aliquot

$\mathrm{Fec}=$ Fraction Continuous extraction in 3 batches

Vrec $=$ Volume of Reconstitution in the mobile phase.

\section{Specific assessment}

In order to demonstrate specificity and selectivity of the method, it was performed in triplicate runs of A. colubrina extract samples subjected to analytical screening, standard marker solution, and mobile phase.

\section{Determination of linearity}

A quercetin stock solution of $200 \mu \mathrm{g} / \mathrm{ml}$ prepared with methanol $70 \%$ was obtained and diluted solutions with concentrations corresponding to $1.4 \mu \mathrm{g} / \mathrm{ml}, 2.1 \mu \mathrm{g} / \mathrm{ml}, 5.6 \mu \mathrm{g} / \mathrm{ml}, 9.8 \mu \mathrm{g} / \mathrm{ml}$, $14 \mu \mathrm{g} / \mathrm{ml}, 18.2 \mu \mathrm{g} / \mathrm{ml}, 22.4 \mu \mathrm{g} / \mathrm{ml}, 26.6 \mu \mathrm{g} / \mathrm{ml}$ to aim linearity. This procedure was performed in triplicate for each concentration level.

\section{Quantification and detection limits}

The lowest amount of the analyte detected in a sample that but not necessarily measured as an exact value is known as the limit of detection (LOD). The lowest amount of analyte in a sample that can be quantitatively determined with suitable precision and accuracy is the limit of quantification (LOQ).

The determination of the limits of quantification and detection was based on the treatment of linearity data by statistical methods. The limit of quantification calculation was obtained from the ratio of the deviation of the linear regression by the inclination of the line, multiplied by 10 . The limit of detection calculation was based on the ratio of the deviation of the linear regression by the slope of line, multiplied by 3.3 .

\section{Precision assessment}

\section{Repeatability}

Repeatability was demonstrated by the injection of 06 quercetincontent samples close to the mean value $(100 \%)$ of the standard linearity curve. The acceptance criterion for this parameter was a relative standard deviation (RSD) with a maximum of $5 \%$.

\section{Intermediate precision}

Intermediate precision was determined from the analysis of 6 samples of the extract, from different analysts and days, with quercetin content close to the mean value $(100 \%)$ of the standard linearity curve. A total of 18 chromatographic runs were performed, 
and the acceptance criterion was at the maximum of 5\% and evaluated the RSD.

\section{Accuracy assessment}

The accuracy of the analytical method was assessed by the postaddition recovery of the quercetin marker standard in extract samples. Three concentration levels (low, medium, and high) were monitored with values corresponding to $20 \%, 100 \%$, and $180 \%$ opposite the accurate concentration obtained. Samples were prepared in triplicate, and injections were performed in duplicate for each concentration level; relative standard deviations (RSD) and recoverability were assessed.

The recovery capacity was calculated from the average concentration of the marker on the standardized extract. Table 1 shows how to calculate standard addition values and percentages of value recovery of the biomarker for all levels.

Table 1: Process of evaluating accuracy of the method

\begin{tabular}{lllll}
\hline \multicolumn{2}{l}{ Recovery of standard added } & & & \\
\hline Level & $\mathbf{A}(\boldsymbol{\mu g} / \mathbf{m l})$ & $\mathbf{B}(\boldsymbol{\mu g} / \mathbf{m l})$ & $\mathbf{C}(\boldsymbol{\mu g} / \mathbf{m l})$ & \% recovery \\
\hline $20 \%$ & {$\left[\mathrm{~W}_{1}\right]$} & {$\left[0.2 \mathrm{~W}_{1}\right]$} & & $\operatorname{Rec} 20 \%=\frac{[C]}{[A+B]} \times 100$ \\
$100 \%$ & {$\left[\mathrm{~W}_{1}\right]$} & {$\left[\mathrm{W}_{1}\right]$} & {$\left[\mathrm{W}_{2}\right]$} & $\operatorname{Rec} 100 \%=\frac{[C]}{[A+B]} \times 100$ \\
$180 \%$ & {$\left[\mathrm{~W}_{1}\right]$} & {$\left[1.8 \mathrm{~W}_{1}\right]$} & & $\operatorname{Rec} 180 \%=\frac{[C]}{[A+B]} \times 100$ \\
\hline
\end{tabular}

Note: A (initial concentration of quercetin in HAE); B (concentration of standard substance chemistry added); C (Recovered concentration of quercetin in $\mathrm{HAE}$; $\left[\mathrm{W}_{1}\right]$ equivalent to the average of the intermediate precision; [ $\left.\mathrm{W}_{2}\right]$ equivalent to the average of the experimental recovery.

\section{Robustness assessment}

In the robustness assessment, variations of oven temperatures in the range $\pm 2{ }^{\circ} \mathrm{C}$ were evaluated, as well as variations in the $\mathrm{pH}$ of the mobile phase varying \pm 0.1 and changes in the mobile phase flow \pm 0.1 . Furthermore, variations in the chromatographic profiles such as retention time, peak area of chromatograms, and ultraviolet spectrum profile of the monitored samples were evaluated. The quantification of the marker in the extract of $A$. colubrina samples was determined with a standard quercetin substance in the same analysis condition of parameter robustness. The RSD was calculated and evaluated.

\section{Stability assessment}

To evaluate the chemical storage stability of solutions of the marker and the extract samples, these were analyzed at zero to $24 \mathrm{~h}$ at room temperature. The chromatographic profile, the analysis of the areas of the chromatographic peaks, the retention time, and the spectral profile of the marker were verified to demonstrate stability.

\section{Statistical analysis}

The statistical analysis of the data was determined through analysis of variance (ANOVA) in software Prism ${ }^{\circledR} 6.01$, considering a level of significance $\alpha=0.05$.

\section{RESULTS AND DISCUSSION}

\section{Development of the analytical method}

\section{Evaluation of analyte separation parameters}

The main pharmacopoeias contains few monographs related to medicinal plants obtained in tropical regions. The standard methods in pharmacopeias are the most indicated for the evaluation quality control of herbal drugs but not exists any reference related to Anadenanthera colubrina [41-42]. Although there are several analytical methods for the analysis of quercetin in extracts, these methodologies cannot be directly applied for any medicinal plant due to the complexity effect of the plant matrix [43-45]. Moreover, not exists any validated method reported to quantify quercetin in $A$. colubrina by HPLC.

Chabariberi and cols. when validated a spectrophotometric methodology for flavonoid analysis in extracts of Maytenus (Celastraceae) and Passiflora (Passifloraceae) have found differences between the absorbances maximum levels with those recorded in the official pharmacopoeias method which quantified total flavonoids expressed in rutin. This variation can be attributed to modifications in the sample pretreatment, as well as to the complexity of the chemical matrix of the analyzed fraction [46].
The evaluation of the validation parameters in this work was preceded by the developing of samples preparation method and extraction of quercetin marker, then the separation conditions by HPLC of the extract fraction of $A$. colubrina was obtained. The chromatographic analysis of the marker was performed initially with a mobile phase system composed by methanol and phosphoric acid, with $\mathrm{pH} 2.5$ varying the ratio of the organic component. Three proportions methanol with $0.01 \%$ phosphoric acid were tested in the order of 30:70,50:50, and 70:30.

In the analytic method development, the HAE sample and the quercetin standard was evaluated under the same separation conditions. Under the conditions of 30:70 and 70:30 were generated overlapping peaks, already under the 50:50 condition it was showed co-elution with the marker peak when compared to the quercetin standard peak, this interference in the co-elution can be characterized by the absence spectral similarity of the main peak under the evaluated conditions. The fig. 1 shows the chromategraphic profiles of each investigated condition.

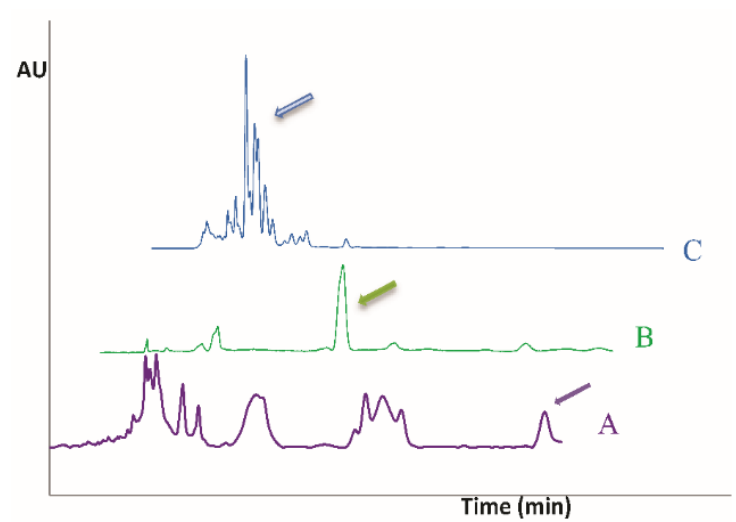

Fig. 1: The chromatographic profile obtained from mobile phase system conditions in the development of the method

According to a review about recent advances in analytical technology applied to quality control of medicinal plants, the complex matrix, the compounds interferences and co-elutions in the chromatographic separations do not allow a reproducible characterization of the extracts [47-48]. In another work with polyphenols, evaluating the chromatographic profiles of natural product, it was demonstrated that there was a great variability in the 
content of the secondary metabolites in real matrices of these products [49].

According to Paiva and cols., in a study evaluating the chromatographic profile of two species of the Plumbaginaceae taxonomic family, the data showed that these species presented common chemical markers, however the chromatographic profiles were different among of the analyzed species, the data, also demonstrated which there are chemical variability on the constituents of the extracts which can differentiate so close species [50].

Xie and cols. validated a method for the simultaneous quantification of three flavonoids and evaluated the chromatographic fingerprints of Flos sophorae immaturus which were collected from different areas from China. The data showed that although the samples shared similar chromatographic patterns, the similarity analysis demonstrated that difference in the constituent's ratios and integrated areas resulted in low similarity values, even if all samples show similar chromatographic fingerprint profiles [51].

The matrix effect is not usually evaluated in validation guidelines, and has been omitted in most of the methods here consider. However, this parameter is a very important parameter to obtain a properly validated and accurate analytical method [52].
The chromatographic analysis of the HAE sample presented interferents that precludes a direct analysis, thus, it was necessary to perform a series of pretreatments in order to remove the interferents such as, fats and pigments which are very common in complex matrices of plants [53-55]. These interfering substances may influence the parameters of selectivity and specificity of analytical validation and can be confirmed when it is seen no clean chromatograms by co-elution of other substances with the main peak and when apolar compounds are retained in the column and chromatographic runtimes are extensive [56-58].

The selection of the best separation condition was based on peak resolution parameters $(\mathrm{Rs})$, retention index $\left(\mathrm{k}^{\prime}\right)$, tailing factor $(\mathrm{T})$, separation efficiency $(\alpha)$, and number of theoretical plates $(N)$ in relation to the main peak monitored, showing the need to optimize the elution condition 50:50 to at 47\%:53\% methanol: phosphoric acid $0.01 \%, \mathrm{pH} 2.5$. The $\mathrm{pH}$ value is justified and consistent with the literature through the employs low $\mathrm{pH}$ and suppression of ionization, assuring complete elution of analyte [59-61].

All evaluated parameters shown in table 2 demonstrate the efficiency of the separation. The peak of the quercetin chemical marker with retention time of 10.14 min was considered as the main peak to calculate the values obtained.

Table 2: Parameters of chromatographic separation efficiency

\begin{tabular}{lll}
\hline Standard peak (RT = 10.1 min) & Mobile phase 47:53 & Recommendation \\
\hline Resolution $(\mathrm{Rs})$ & 2.07 & $\mathrm{Rs}>1.5$ \\
Retention factor $\left(\mathrm{K}^{\prime}\right)$ & 3.76 & $1 \leq \mathrm{K}^{\prime} \leq 10$ \\
Tailing factor $(\mathrm{T})$ & 1.020 & $0.5 \leq \mathrm{T} \leq 2$ \\
Separation efficiency $(\alpha)$ & 1.23 & $\alpha>1$ \\
Theoretical plates $(\mathrm{N})$ & 3878 & $\mathrm{~N}>2000$ \\
\hline
\end{tabular}

Note: Mobile phase system consisting of methanol $47 \%$ and 53\% Phosphoric acid $0.01 \%$. RT (real time).

As shown in table 2, the optimized conditions generate chromatograms with an ideal range for retention factors $(1.0<\mathrm{k}<10)$, separation efficiency values greater than 1.0, and resolution above 2.0 , confirming the quality of separation. The efficiency of the column was optimum, and the peaks of the rejection factor between 0.5 and 2.0 demonstrate the run. Analytical methods confirm good results in the efficiency parameters, as obtained in the value of 3878 theoretical plates higher than 2000 .

Timóteo and cols. In validating a method for analysis of herbal teas found that a single chromatographic peak corresponded to three constituents. The accurate separation of the constituents was only possible after varying the separation conditions using stationary phase with different characteristics and dimensions and monitoring of the spectral purity, as realized in the present [62].

\section{Evaluation of analyte recovery}

The recovery of the marker investigated the extractive potential of solvents with different polarities: dichloromethane, ethyl acetate, and chloroform on the fluid extract matrix. Extraction with ethyl acetate showed a single-phase system with difficult separation, extraction not being possible. In contrast, the chloroform solvent was able to extract with limitation and variation in the recovery and reproducibility of the analyte, even with the use of continuous multiple extractions. Otherwise, dichloromethane was suitable for extracting the analyte efficiently after three extractions using a continuous multiple-extraction system.

The recovery of the method was also evaluated through different aqueous fractions of 0.5 to $2 \mathrm{ml}$ of HAE, in which the recovery and the selectivity of the marker in the extraction were determined. The best recovery was obtained in $0.5 \mathrm{ml}$ fraction with three consecutive extraction steps, obtaining a separation of the marker with selectivity and adequate recovery. The final step of the sample preparation was the evaporation at $50{ }^{\circ} \mathrm{C}$ of $4.0 \mathrm{ml}$ dichloromethane fraction followed by reconstitution of the same in the mobile phase.
The reconstituted solution was filtered and transferred to vials to be injected into the chromatographic system.

A study that evaluated extraction of quercetin and kaempferol in plant matrix concluded that ethyl acetate solvent was insufficient to extract the flavonoids by liquid-liquid extraction, which is consistent with the data obtained in this work [63]. Several papers present the methanol solvent as optimum in the extraction of flavonoids [51, $62]$, but due to the aqueous nature of the extract preference was given to a solvent that produced a heterogeneous system with the fluid extract. In this work, the choice by chloroform and dichloromethane was based on the principle of miscibility between the fluid extract and these solvents and still on the chemical affinity these solvents have for flavonoid compounds [64-65].

\section{Evaluation of the method validation parameters}

\section{Assessment of specificity}

The specificity of the method was based on comparing its retention times and UV-spectra in the $200-400 \mathrm{~nm}$ range with the quercetin standard. Also compared were the spectral and chromatographic profiles of blank from the mobile phase, quercetin standard, and sample extract.

The choice of an appropriate detection wavelength was of great importance to ensure accurate detection of the quercetin and to achieve specificity. The UV spectrum of the compound was detected at 370 nm by diode array detector under the chromatographic conditions as described in methodology. The specificity analysis was demonstrated as shown in fig. 2 and the results are consistent with those reported in the literature [52].

The analysis of chromatographic profiles of the standard and sample showed that the method was specific in separation and identification marker quercetin by overlapping chromatographic profiles. The spectral analysis of the sample and standard quercetin, shown in fig. 2 and 3 demonstrates the specificity by the similarity of the spectral 
profile and identification of the wave number with maximum absorbance at $370 \mathrm{~nm}$.

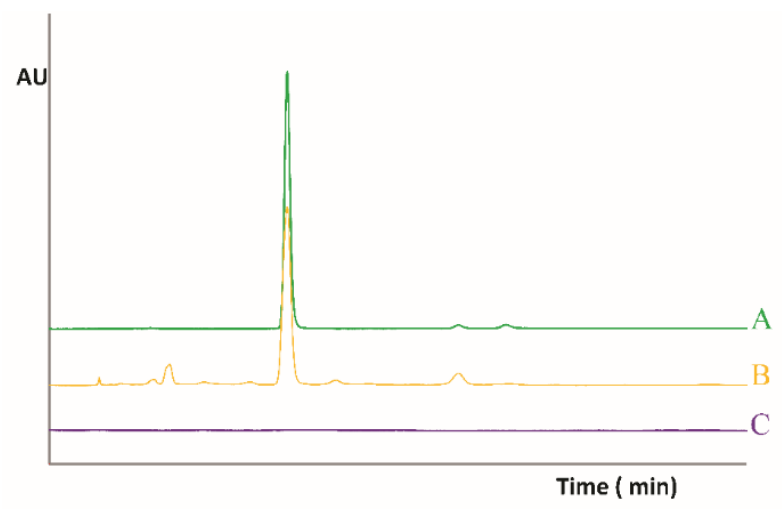

Fig. 2: Chromatographic profiles of the quercetin solution standard (A), solution sample (B) and blank (C)

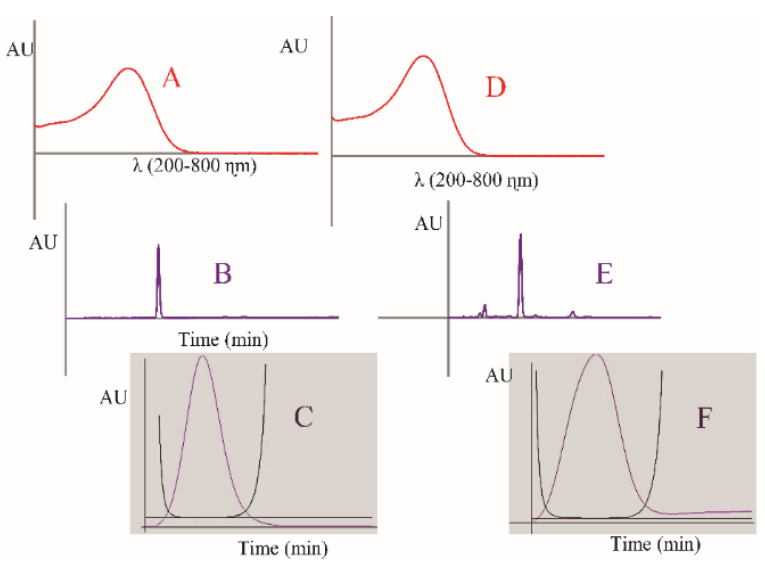

Fig. 3: Spectral profile of the quercetin standard (A, B, C) and the marker monitored in the extract of the leaves of $A$. colubrina (D, E,F)
The ultraviolet spectrum indicated on graphics A and D were evidence of similar spectral profiles with a maximum absorbance of $370 \mathrm{~nm}$. The graphics $\mathrm{C}$ and $\mathrm{F}$ demonstrate spectral purity for both chromatographic peaks, shown in profiles B and E, which represent the chromatographic run of the sample and standard. In addition, specificity was confirmed by detector photodiode arrangement, which demonstrated that quercetin peaks have no co-elution of any additional peak, with values of peak purity greater than 0.999 . The confirmation of the identification of the monitored peak in the chromatographic profiles is visualized in fig 3 .

Based on the chromatographic and spectral profiles observing peak retention time, spectral profiles similarity, and spectral purity, it was possible to demonstrate the specificity of the same proposed method.

\section{Determination of sensitivity}

Both the limit of detection (LOD) and the limit of quantitation (LOQ) were also determined with linearity and statistical tool applications; the limits of quantification and detection were respectively calculated to obtain values of $0.81 \mu \mathrm{g} / \mathrm{ml}$ and $0.27 \mu \mathrm{g} / \mathrm{ml}$. similar results were reported in the development of the analytical method for quercetin determination in the Platycladus orientalis (L.). At cited work obtaining LOD values of $0.005 \mu \mathrm{g} / \mathrm{ml}$ and LOQ values equivalent to $0.01 \mu \mathrm{g} / \mathrm{ml}$ [66]. The values difference in relation to the proposed method can be associated with several factors such as extractive matrix complexity, the method of determination of LOD parameters and LOQ up to detector sensitivity. Mattonai and cols. validated a method by HPLC-DAD and HPLC-MS for determination of polyphenols in monofloral honey, obtaining LOD and LOQ for quercetin equivalent to 0.2 and $0.7 \mathrm{ug} / \mathrm{ml}$ respectively. These results of cited article are in agreement with data of the analytical method validation proposed in this work [67].

\section{Determination of linearity}

Table 3 shows the plotted reference values of linearity with average areas obtained for each concentration level. The linearity of the method was demonstrated by evaluating the linear correlation $\mathrm{R}^{2}$ coefficient obtained by linear regression and analysis of single factor variance, where it was shown that the $F$ Tabulated (Critical) is greater than the calculated $\mathrm{F}$ value, for a level of significance of $\alpha>0.05$. Based on ANOVA, the variations between values obtained from the three curves were not significant.

Table 3: The Mean linearity obtained from triplicate injections of solutions containing quercetin as reference standard

\begin{tabular}{lll}
\hline Level (\%) & Concentrations $(\boldsymbol{\mu g} / \mathbf{m l})$ & Mean área \pm RSD \\
\hline 10 & 1.4 & $75218 \pm 4.4$ \\
15 & 2.1 & $116212 \pm 3.1$ \\
40 & 5.6 & $308288 \pm 3.1$ \\
70 & 9.8 & $552019 \pm 1.3$ \\
100 & 14 & $796704 \pm 1.7$ \\
130 & 18.2 & $1037895 \pm 0.1$ \\
160 & 22.4 & $1268748 \pm 0.2$ \\
190 & 26.6 & $1504493 \pm 1.2$ \\
\hline
\end{tabular}

Note: ${ }^{\mathrm{a}} \mathrm{n}=3$ injections, RSD (Relative standard deviation).

The mean linearity curve and linear regression equation are shown in fig. 4 . The linearity met the requirement of $\mathrm{R}^{2}$ greater than 0.99 as recommended in the validation guides of analytical methods. The data that generated average linearity are available in the complementary information. The analysis of variance as a single factor showed a value of $\mathrm{F}$ (critical) that was higher than the value of $\mathrm{F}$ calculated, indicating that the variations among the data for the three curves were not significant. The statistical data of linearity were in agreement with ICH guidelines for analytical methods. Similar results were reported by Blainski and cols. when validating a method by HPLC-DAD for gallocatechin and epigallocatechin quantification in rhizomes from Limonium brasiliense obtained linearity results similar to this work. The regression coefficient (R2) for two markers were above 0.99 , calculated F-value is lower than critical F-value, the analysis of variance showed p-value below $0.001[68]$.

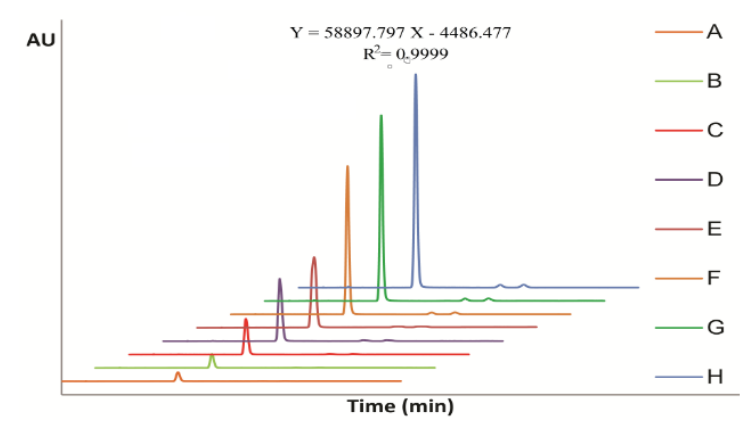

Fig. 4: Chromatographic profiles of linearity obtained with 8 points at increasing concentrations and linear regression equation with $R^{2}$ value 


\section{Precision assessment}

\section{Repeatability and intermediate precision}

Repeatability was evaluated with the same analyst, day, and chromatograph with six runs from the extract sample, allowing the proposed method to exhibit adequate precision for quercetin, with the percentage of RSD overall better that $5 \%$.

The intermediate precision was evaluated in three days with a total of 18 runs of the extract obtained from the extract sample. The results obtained from the precision are plotted in table 4 . These data demonstrated intermediate precision and met the requirements for the analytical method validation guidelines. According to the statistical analysis, there were no significant variations among the data, where $p$ value between rows and columns is above 0.05 , and critical $\mathrm{F}$ values are smaller than the values of the tabled $\mathrm{F}$, proving that the method developed is accurate under the established conditions. The overall composition of the extract was the same in all the samples analyzed, assure reproducibility and highlighted the repeatability and intermediate precision as an important parameter for quantitative analysis of $A$. Colubrina. These results are according to the official literature for methods of validating [69] and demonstrate that the developed method can be satisfactorily used for determination of quercetin in the A. colubrina samples extracts.

Table 4: Precision assessment

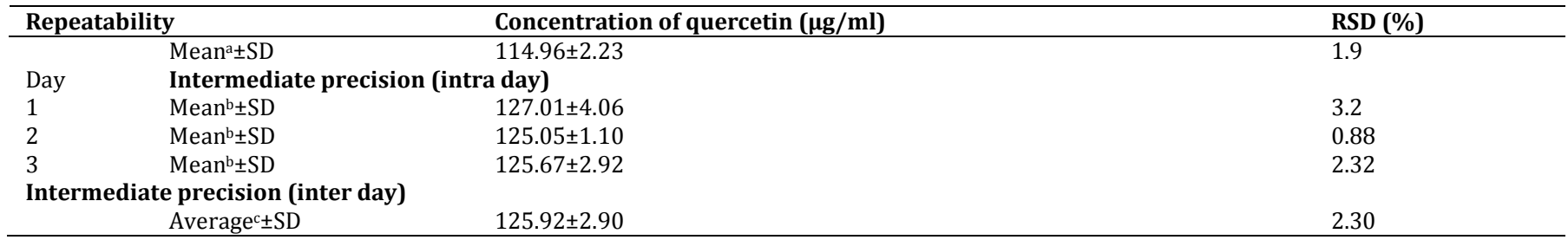

Note: $\mathrm{a}, \mathrm{b} n=6$; $\mathrm{c} n=18$, SD (Standard deviation) and RSD (Relative standard deviation).

\section{Accuracy assessment}

The accuracy of the analytical method was evaluated by adding known amounts of the marker quercetin in three concentrations: low, medium, and high. The standard addition had values of $20 \%$, $100 \%$, and $180 \%$ compared with mean values of the concentration obtained in the matrix. In table 5 , the data are plotted for the accuracy assessment of the proposed method. It contains the values of average areas (duplicate) obtained for each level of accuracy with their respective values, information about the true value concentration of samples with standard addition, and experimental values obtained after recovery of the marker expressed in percentages. Statistical analysis confirmed that the data were within the acceptance criteria.

Table 5: Evaluate of recovery and accuracy

\begin{tabular}{lllll}
\hline Level of addition (\%) & $\mathbf{A}(\boldsymbol{\mu g} / \mathbf{m l}) \pm$ SD & $\mathbf{B}(\boldsymbol{\mu g} / \mathbf{m l}) \pm$ SD & $\mathbf{C}(\boldsymbol{\mu g} / \mathbf{m l}) \pm$ SD & Recovery (\%) \pm SD \\
\hline $20 \%^{\mathrm{a}}$ & $125.9 \pm 2.90$ & 25.2 & $147.3 \pm 4.3$ & $97.5 \pm 2.7$ \\
RSD (\%) & 2.3 & & 2.9 & 2.7 \\
$100 \%$ (1) & & 125.9 & $238.15 \pm 4.3$ & $93.8 \pm 4.1$ \\
RSD (\%) & & 226.6 & 1.8 & 4.4 \\
$180 \%{ }^{\mathrm{c}}$ & & & $327.5 \pm 11.5$ & $92.5 \pm 3.4$ \\
RSD (\%) & & 3.4 & 3.7 \\
\hline
\end{tabular}

Note: A (concentration of quercetin in matrix of the extract); B (concentration of standard quercetin added); C (amount recovered). a,b, $\mathrm{n}=18$, SD (Standard deviation) and RSD (Relative standard deviation).

The quercetin marker was recovered by partitioning fluid extract and dichloromethane solvent using liquid liquid extraction. The pretreatment of the sample was based on the principle of chemical similarity, where the solvent removed interfering compounds and recovered the quercetin from the phytocomplex of $A$. colubrina [50].

The assessment of recovery is a determining parameter in the safety of analytical measures and critical step in the validation [39]. Mattila and colleagues determined the amount of quercetin in apple, red wine and green tea obtaining recovery of $79 \%, 104 \%$ and $82 \%$ respectively, compared to $93 \%$ reference sample, which demonstrates the variability of extraction in different matrices and the importance of establishing strategies for the removal of interferences and total extraction of the analytes of interest [70]. The recovery of analytes in complex matrices by methodology similar to the one performed in the present research presented recovery range between 92 and 94\% with $\mathrm{RSD}<5 \%$ [71]. Tang and cols. evaluating the recovery of the quercetin marker in Ginkgo biloba extract samples, obtained recovery values between 97.2 and $101.4 \%$ with RSD $=2 \%$ [72]. Another study, evaluating different techniques of extracting the flavonoids quercetin and kaempferol in plant matrices, presented values of recovery of these analytes after standard addition between 96.8 and $98.2 \%$ [63]. These researches confirm the recovery values of quercetin obtained for samples of $A$. colubrina extract.

\section{Robustness assessment}

The robustness was determined using the overall mean, standard deviations, relative standard deviations (RSD \%) for each parameter. Samples were prepared in triplicate and the analyses were performed in duplicate for each condition evaluated.

The most typical variations on robustness considered in analytical methods validation are the column oven temperature, the composition, the $\mathrm{pH}$ and the flow of the mobile phase [52].

In the evaluation of the influence of variations in the column oven temperature, on the areas of the peaks, it was observed that this parameter in the evaluated conditions $\pm 2{ }^{\circ} \mathrm{C}$ did not influence the results and therefore, of marker content.

In the influence of variations in the flow of the mobile phase on the peak areas, it was observed that the parameter evaluated under the conditions of $0.1 \mathrm{ml}$ into more or less did not influence the results area of the analyte.

In the evaluation of the influence of variations in the $\mathrm{pH}$ of the mobile phase on areas of the peaks, it was observed that this parameter in the evaluated conditions \pm 0.1 influenced the results of area of the peak analyte. This variation can be attributed to 
ionization problems of the marker molecule, and therefore $\mathrm{pH}$ is a parameter to be strictly monitored for the proposed method.

In the statistical analysis, ANOVA was chosen with a 95\% of confidence interval due to the biological matrix studied being complex. Therefore, at a level $\alpha$ of 0.05 , there is a significant difference in the robustness dataset, considering that $F$ value is calculated higher than F (Critical) should be necessary evaluated possible variations in the robustness parameter. The results of the robustness evaluation are presented in table 6.

Table 6: Evaluation of conditions of column oven temperature, flow of the mobile phase and pH in robustness of the method

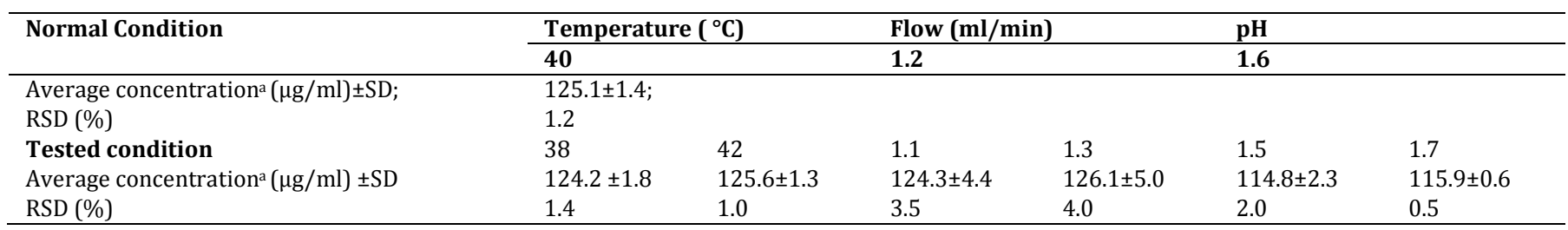

Note: ${ }^{a} \mathrm{n}=6 . \mathrm{SD}$ (Standard deviation) and RSD (Relative standard deviation).

Table 7: Stability assessment of sample extracts solutions

\begin{tabular}{|c|c|c|}
\hline & Concentrati & \\
\hline & $\mathrm{T}_{0}$ & $\mathrm{~T}_{24}$ \\
\hline $\begin{array}{l}\text { Average concentration a } \\
(\mu \mathrm{g} / \mathrm{ml}) \pm \mathrm{SD} ; \mathrm{RSD}(\%)\end{array}$ & $\begin{array}{l}115.0 \pm 2.23 \\
1.9\end{array}$ & $\begin{array}{l}114.0 \pm 1.92 \\
1.7\end{array}$ \\
\hline
\end{tabular}

Note: ${ }^{a} \mathrm{n}=6$, SD (Standard deviation) and RSD (Relative standard deviation). $\mathrm{T}_{0}$ (Sample solution in time zero), $\mathrm{T}_{24}$ (Sample solution after $24 \mathrm{~h}$ the time zero).

\section{Evaluation stability}

The stability of the sample extract was analyzed at 0 and $24 \mathrm{~h}$ after sample preparation. The data showed that the samples in these conditions were stable for at least $24 \mathrm{~h}$. The stability data are plotted in table 7. The sample solution analyzed exhibited values of concentrations of quercetin at 115.0 and $114.0 \mu \mathrm{g} / \mathrm{ml}$, respectively for the test time. The coefficient of variation of the stability data of the analyte did not exceed $2.0 \%$.

These results are according to the minimal official guides requirements for methods of validating [39] and demonstrate that the developed method can be suitably used for analysis of quercetin in the A. colubrina extract samples.

\section{CONCLUSION}

In this paper, the analytical method of HPLC-DAD was validated for quantitative determination of quercetin on an extract of $A$. colubrina allowing selective analysis free of interferents. The analytical method proved to be specific, selective, linear, precise, accurate, robust, fast, and reliable. The data obtained suggest that the method can be applied as an appropriate analytical tool in the quality control of herbal medicines obtained from extracts of $A$. colubrina.

\section{ACKNOWLEDGMENT}

The authors thanks the National Council of Scientific and Technological Development (CNPq) for project financing, Development Institute in Pharmaceutical Studies (IDEF) for financial support and the Federal University of Paraíba for supporting the infrastructure of laboratories. The authors also thanks to the Prof. Alessandra Vieira Lacerda for her important contribution in the botanical identification of the species studied.

\section{CONFLICT OF INTERESTS}

The authors declare no conflict of interest

\section{REFERENCES}

1. Albuquerque UP, Medeiros PM, Almeida ALS, Monteiro JM, Neto EMFL, Melo JG, et al. Medicinal plants of the caatinga (semiarid) vegetation of NE Brazil: A quantitative approach. J Ethnopharmacol 2007;114:325-54.

2. Ortolani FA, Melloni MN, Mariotto GCFG, Moro JR. Caracterização citogenética em Anadenanthera colubrina (Vell.)
Brenan (Mimosoideae) e Guazuma ulmifolia Lam. (Sterculiaceae). Acta Botanica Brasilica 2010;24:299-303.

3. Viana ML, Giamminola E, Russo R, Ciaccio M. Morphology and genetics of Anadenanthera colubrina var. cebil (Fabaceae) tree from Salta (Northwestern Argentina). Rev Biol Trop 2014;62:757-63.

4. Iacomini M, Jones C, Gorin PAJ, Delgobo C. Gum heteropolysaccharide and free reducing mono and oligosaccharides of Anadenanthera colubrina. Phytochemistry 1998;47:1207-14.

5. Hajdu Z, Hohmann J. An ethnopharmacological survey of the traditional medicine utilized in the community of porvenir, Bajo Paragua Indian Reservation, Bolivia. J Ethnopharmacol 2012;139:838-57.

6. Júnior WSF, Ladio AH, Albuquerque UP. Resilience and adaptation in the use of medicinal plants with suspected antiinflammatory activity in the Brazilian Northeast. J Ethnopharmacol 2011;138:238-52.

7. Pessoa WS, Estevão LRM, Simões RS, Barros MEG, Mendonça FS, Evêncio LB, et al. Effects of angico extract (Anadenanthera colubrina var. cebil) in cutaneous wound healing in rats. Acta Cirúrgica Brasileira 2012;27:655-70.

8. Araújo TAS, Alencar NL, Amorim ELC, Albuquerque UP. A new approach to study medicinal plants with tannins and flavonoids contents from the local knowledge. J Ethnopharmacol 2008;120:72-80.

9. Moretão MP, Zampronio AR, Gorin PA, Iacomini M, Oliveira MBM. Induction of secretory and tumoricidal activities in peritoneal macrophages activated by an acidic heteropolysaccharide (ARAGAL) from the gum of Anadenanthera colubrina (Angico branco). Immunol Lett 2004;93:189-97.

10. Moretão MP, Buchi DF, Gorin PA, Iacomini M, Oliveira MBM. Effect of an acidic heteropolysaccharide (ARAGAL) from the gum of Anadenanthera colubrina (Angico branco) on peritoneal macrophage functions. Immunol Lett 2003;89:175-85.

11. Nogueira C, Dieamant GC, Stasi LCD, Polezel MA, Pereda MCV, Eberlin S. Uso de extrato de angico branco (Piptadenia colubrina) em formulações cosméticas e farmacêuticas como agente antinflamatório e hidratante para a pele. BR PI0702480-0 A-2; 2009.

12. Singh A, Puri D, Kumar B, Singh SK. Heat shock proteins: knowledge so far and its future prospects. Asian J Pharm Clin Res 2016;9:17-24. 
13. Oliveira TT, Nagem EQL. Cicatrizante (Biofarmaco) Universidade federal de viçosa, Universidade federal de ouro Preto. BR PI0605952-0A; 2008.

14. Donno D, Mellano MG, Cerutti AK, Beccaro GL. Biomolecules and natural medicine preparations: analysis of new sources of bioactive compounds from Ribes and Rubus spp. Buds. Pharmaceuticals 2016;9:7.

15. Forim RM, Perlatti B, Costa ES, Magnani RF, Souza GD. Concerns and considerations about the quality control of natural products using chromatographic methods. Curr Chromatogr 2015;2:20-31.

16. Migliato KF, Corrêa MA, Salgado HRN, Tognolli JO, Sacramento LVS, Mello JCPD, et al. Planejamento experimental na otimização da extração dos frutos de Syzygium cumini (L.) skeels. Quim Nova 2011;34:695-9.

17. Jain HK, Deore DD. Bioanalytical method development and validation for estimation of clopidogrel bisulfate in human plasma by RP-HPLC. Int J Appl Pharm 2016;8:18-21.

18. Tshibangu PT, Kapepula PM, Kapinga MK, Lupona HK, Ngombe NK, Kalenda DT, et al. Finger printing and validation of a LCDAD method for the analysis of biflavanones in Garcinia kolabased antimalarial improved traditional medicines. J Pharm Biomed Anal 2016;128:382-90.

19. Aparna CH, Madhavi LN, Supriya P, Gowrisankar D. A review on matrix assisted laser desorption/ionization mass spectroscopy. Asian J Pharm Clin Res 2015;8:28-33.

20. Júnior JOCS, Costa RMR, Teixeira FM, Barbosa WLR. Quality control of herbal medicines and related areas. Ed. Yukihiro Shoyama, Intech: Rijeka, Croatia; 2011. p. 63-81.

21. Matamoros V, Calderón-Preciado D, Domínguez C, Bayona JM. Analytical procedures for the determination of emerging organic contaminants in plant material: a review. Anal Chim Acta 2012;722:8-20.

22. Mokhtar M, Russo M, Cacciola F, Donato P, Giuffrida D, Riazi A, et al. Capsaicinoids and carotenoids in Capsicum annuum L.: optimization of the extraction method, analytical characterization, and evaluation of its biological properties. Food Anal Methods 2016;9:1381-90.

23. Van Beek TA. Chemical analysis of Ginkgo biloba leaves and extracts. J Chromatogr A 2002;967:21-55.

24. LeDoux M. Analytical methods applied to the determination of pesticide residues in foods of animal origin. A review of the past two decades. J Chromatogr A 2011;1218:1021-36.

25. Murugan S, Pravallika N, Sirisha P, Chandrakala K. A review on bioanalytical method development and validation by using LCMS/MS. Int J Curr Pharm Clin Res 2013;3:13-7.

26. Morzycka B. Simple method for the determination of trace levels of pesticides in honey bees using matrix solid-phase dispersion and gas chromatography. J Chromatogr A 2002;982:267-73.

27. Shi ZQ, Song DF, Li RQ, Yang H, Qi LW, Xin GZ, et al. Identification of effective combinatorial markers for quality standardization of herbal. J Chromatogr A 2011;1345:78-85.

28. Barni ST, Cechinel-Filho V, Couto AG. Caracterização química e tecnológica das folhas, caules e planta inteira da Ipomoea pescaprae (L.) R. Br., Convolvulaceae, como matéria-prima farmacêutica. Brazilian J Pharmacogn 2009;19:865-70.

29. Dias FS, David JM, David JP. Determination of phenolic acids and quercetin in brazilian red wines from vale do são francisco region using liquid-liquid ultrasound-assisted extraction and HPLC-DAD-MS. J Braz Chem Soc 2016;27:1055-9.

30. Afonso S, Pisano PL, Silva FB, Scaminio IS, Olivieri AC. Discrimination of Annon amuricata and Rollinia mucosa extracts by using multivariate curve resolution and partial least-squares regression of liquid chromatography-diode array data. J Braz Chem Soc 2015;26:2241-8.

31. Monteiro JM, Souza JSN, Neto EMFL, Scopel K, Trindade EF. Does total tannin content explain the use value of spontaneous medicinal plants from the Brazilian semi-arid region? Rev Bras Farmacogn 2014;24:116-23.

32. Leite VI, Oliveira MCD, Figueredo JG, Farias PAM, Relison S, Matias EFF, et al. Caracterização química e avaliação da atividade antioxidante, antifúngica e moduladora do extrato etanólico de Anadenanthera macrocarpa (BERTH) BRENAN. Rev Cubana Farm 2015;49:719-33.

33. Santana AL, Maranhão CA, Santos JC, Cunha FM, Conceição GM Bieber LW, et al. Antitermitic activity of extractives from three Brazilian hardwoods against Nasutitermes corniger. Int Biodeterior Biodegrad 2010;64:7-12.

34. Holden JM, Bhagwat SA, Haytowitz DB, Gebhardt SE, Dwyer JT, Peterson J, et al. Development of a database of critically evaluated flavonoids data: application of USDA's data quality evaluation system. J Food Compos Anal 2005;18:829-44.

35. Landim LP, Feitoza GS, da Costa JGM. Development and validation of a HPLC method for the quantification of three flavonoids in a crude extract of Dimorphandra gardneriana. Rev Bras Farmacogn 2013;23:58-64.

36. Noriega P, Mafud DF, Strasser M, Kato ETM, Bacchi EM. Passiflora alata Curtis: a Brazilian medicinal plant. Bol Latinoam Caribe Plant Med Aromat 2011;10:398-413.

37. Valentão P, Andrade PB, Areias F, Ferreres F, Seabra RM. Analysis of vervain flavonoids by hplc/diode array detector method. Its application to quality control. J Agric Food Chem 1999;47:4579-82

38. Vechia CAD, Morais B, Schonell AP, Diel KAP, Faust C, Menin C, et al. Isolamento químico e validação analítica por cromatografia líquida de alta eficiência de quercitrina em Solidago chilensis Meyen (Asteraceae). Rev Bras Plant Med 2016;18:288-96.

39. Guideline, ICH Harmonized Tripartite. "Validation of analytical procedures: text and methodology"(Q2 (R1); 2005. p. 1-17.

40. Chaurasia S, Kulkarni GT, Shetty LN, Pawar VK. Development and validation of UV spectroscopic method for the quick estimation of piper betle leaf (pbl) extract. Int J Curr Pharm Res 2011;3:57-9.

41. Pandey A, Tripati S. Concept of standardization, extraction and pre phytochemical screening strategies for herbal drug. J Pharmacogn Phytochem 2014;2:115-9.

42. Folashade O, Omoregie H, Ochogu P. Standardization of herbal medicines-a review. Int J Biodivers Conserv 2012;4:101-12.

43. Hasler A, Sticher O, Meier B. Identification and determination of the flavonoids from Ginkgo biloba by high-performance liquid chromatography. J Chromatogr A 1992;605:41-8.

44. Wolfender JL. HPLC in natural product analysis: the detection issue. Planta Med 2009;75:719-34.

45. Tsao R. Chemistry and biochemistry of dietary polyphenols. Nutrients 2010;2:1231-46.

46. Chabariberi RDA, Pozzi A, Zeraik ML, Yariwake JH. Spectrometric determination of flavonoids from Maytenus (Celastraceae) and Passiflora (Passifloraceae) leaves and comparison with an HPLC-UV method. Rev Bras Farmacogn 2009;19:860-4.

47. Steinmann D, Ganzera M. Recent advances on HPLC/MS in medicinal plant analysis. J Pharm Biomed Anal 2011;55:744-57.

48. Dai J, Mumper RJ. Plant phenolics: extraction, analysis and their antioxidant and anticancer properties. Molecules 2010; 15:7313-52.

49. Pellati F, Orlandini G, Pinetti D, Benvenuti S. HPLC-DAD and HPLC-ESI-MS/MS methods for metabolite profiling of propolis extracts. J Pharm Biomed Anal 2011;55:934-48.

50. Paiva SRD, Fontoura LDA, Figueiredo MR, Mazzei JL, Kaplan MAC. Chromatographic profile of two plumbaginaceae species: Plumbago scandens L. and Plumbago auriculata LAM. Quim Nova 2002;25:717-21.

51. Xie Z, Lam S, Wu J, Yang D, Xu X. Chemical fingerprint and simultaneous determination of flavonoids in Flos Sophorae Immaturus by HPLC-DAD and HPLC-DAD-ESI-MS/MS combined with chemometrics analysis. Anal Methods 2014;6:4328-35.

52. Spínola V, Llorent-Martínez EJ, Castilho PC. Determination of vitamin C in foods: current state of method validation. J Chromatogr A 2014;1369:2-17.

53. Hsu BY, Lin SW, Inbaraj BS, Chen BH. Simultaneous determination of phenolic acids and flavonoids in Chenopodium formosanum Koidz. (djulis) by HPLC-DAD-ESI-MS/MS. J Pharm Biomed Anal 2017;132:109-16.

54. Saptarini NYIM, Herawati IRMAE, Permatasari ULIY. Total flavonoids content in acidified extract of flowers and leaves of 
gardenia (Gardenia jasminoides ellis) Asian J Pharm Clin Res 2016;9:213-5

55. Schieber A, Keller P, Carle R. Determination of phenolic acids and flavonoids of apple and pear by high-performance liquid chromatography. J Chromatogr A 2001;910:265-73.

56. Pradeepa M, Kalidas V, Geetha N. Qualitative and quantitative phytochemical analysis and bactericidal activity of pelargonium graveolens l'her. Int J Appl Pharm 2016;8:7-11.

57. Amorim MR, Rinaldo D, do Amaral FP, Vilegas W, Magenta MAG, Junior GMV, et al. HPLC-DAD based method for the quantification of flavonoids in the hydroethanolic extract of Tonina fluviatilis Aubl. (Eriocaulaceae) and their radical scavenging activity. Quim Nova 2014;37:1122-7.

58. Steinmann D, Ganzera M. Recent advances on HPLC/MS in medicinal plant analysis. J Pharm Biomed Anal 2011;55:744-57.

59. Chabariberi RDA, Pozzi A, Zeraik ML, Yariwake JH. Spectrometric determination of flavonoids from Maytenus (Celastraceae) and Passiflora (Passifloraceae) leaves and comparison with an HPLC-UV method. Rev Bras Farmacogn 2009;19:860-4.

60. Tsao R. Chemistry and biochemistry of dietary polyphenols. Nutrients 2010;2:1231-46.

61. Dias ALDS, Souza JNSD, Rogez H. Purification of phenolic compounds from Inga edulis leaves using solid-phase extraction: major compounds quantification and antioxidant capacity evaluation. Quím Nova 2010;33:38-42.

62. Timóteo P, Karioti A, Leitão SG, Vincieri FF, Bilia AR. A validated HPLC method for the analysis of herbal teas from three chemotypes of Brazilian Lippia alba. Food Chem 2015;175:366-73.

63. Skalicka-Woźniak K, Szypowski J, Głowniak K. HPLC analysis of kaempherol and quercetin derivatives isolated by different extraction techniques from plant matrix. J AOAC Int 2011;94:17-21.

64. Lee JY, Lee MS, Choi JW, Shin TS, Woo HC, Kim HR. Dichloromethane fraction of Laminaria japonica ethanolic extract inhibits lipopolysaccharide-induced nitric oxide synthase and cyclooxygenase-2 expression in RAW 264.7 cells

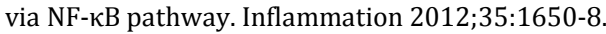

65. Mutheeswaran S, Kumar PS, Yuvaraj P, Duraipandiyan V, AlDhabi NA, Balakrishna K, et al. Screening of some medicinal plants for anticariogenic activity: an investigation on bioactive constituents from Jatropha gossypifolia (L.) root. Biocatal Agric Biotechnol 2017:10:161-6.

66. Lu YH, Liu ZY, Wang ZT, Wei DZ. Quality evaluation of Platycladus orientalis (L.) Franco through simultaneous determination of four bioactive flavonoids by highperformance liquid chromatography. J Pharm Biomed Anal 2006;41:1186-90

67. Mattonai M, Parri E, Querci D, Degano I, Ribechini E. Development and validation of an HPLC-DAD and HPLC/ESI-MS 2 method for the determination of polyphenols in monofloral honeys from Tuscany (Italy). Microchem J 2016;126:220-9.

68. Blainski A, Antonelli-Ushirobira TM, Godoy G, Leite-Mello EV, Mello JC. Pharmacognostic evaluation, and development and validation of a HPLC-DAD technique for gallocatechin and epigallocatechin in rhizomes from Limonium brasiliense. Rev Bras Farmacogn 2017;27:162-9.

69. Escarpa A, González MC. Approach to the content of total extractable phenolic compounds from different food samples by comparison of chromatographic and spectrophotometric methods. Anal Chim Acta 2001;427:119-27.

70. Mattila P, Astola J, Kumpulainen J. Determination of flavonoids in plant material by HPLC with diode-array and electro-array detections. J Agric Food Chem 2000;48:5834-41.

71. Escarpa A, González MC. Evaluation of high-performance liquid chromatography for determination of phenolic compounds in pear horticultural cultivars. Chromatographia 2000;51:37-43.

72. Tang D, Yang D, Tang A, Gao Y, Jiang X, Mou J, et al. Simultaneous chemical fingerprint and quantitative analysis of ginkgo biloba extract by HPLC-DAD. Anal Bioanal Chem 2010;396:3087-95.

\section{How to cite this article}

- Valmir Gomes De Souza, Fabrício Havy Dantas De Andrade, Fabio Santos De Souza, Rui Oliveira Macedo. Analytical method by HPLC-dad allows quantification of quercetin marker in standardized extract of Anadenanthera colubrina var. cebil. Int J Pharm Pharm Sci 2017;9(8):47-55. 